\title{
PROBLEMS IN THE FUTURE ORGANIZATION OF MEDICAL PRACTICE*
}

\author{
David Mechanic $\dagger$
}

Despite vast and growing expenditures for medical care in the United States, there is an emerging consensus among observers that a state of crisis exists. The deficiences in our present system of delivering health care services have become more visible as a consequence of difficulties in the successful implementation of Medicare and Medicaid, two federally subsidized programs that contribute approximately ten billion dollars a year to annual expenditures for health care. ${ }^{1}$ These programs have focused attention on such issues as growing inflation in medical care costs; the inefficiency in the organization of medical care services; special problems in meeting the health needs of particular groups such as the poor and persons in rural areas; difficulties in administering the work of doctors and other professionals; scarcity of special facilities such as nursing homes that meet adequate standards; and the enormity of administrative details involved in these programs.

It is now widely appreciated that continued expansion of funds for medical care services-without associated incentives for major changes in the organization and delivery of medical care-will contribute to significant inflation in the health area and is unlikely to succeed in meeting population needs for health care. In light of this, it is ironic that more recent discussions of national health insurance have for the most part failed to address themselves to the significant organizational problems that any large new program can be expected to encounter. Most of the discussion has focused on the cost of alternative financing mechanisms and the scope of coverage without detailed concern for the components of health service or how they might best be provided. 2

* Supported in part by PHS Grant No. HS 00253, National Center for Health Services Research and Development.

+ B.A. 1956, City College of New York; M.A. 1957, Ph.D. 1959, Stanford University. Professor of Sociology and Director of Graduate Training in Medical Sociology, University of Wisconsin. Author, Mental Health and Sociat Policy (I969), Medical Sociology (I968), Students Under Stress (Ig62); coauthor [with Henry Latané, George Strother, and George Strauss], Sociaz Scrence of Organzations (1963). Chairman, Medical Sociology Section, American Sociological Association.

1 See generally Staff of Senate Comm. on Finance, 9ist Cong., 2D Sess., Medicare and Medicaid: Problexs, Issues, and Alternatives (Comm. Print 1970) [hereinafter cited as Senate Staff Report].

2 See S. Waldman, Tax Credits for Private Health Insurance: Estmmates of Eligibility and Cost Under Five Alternative Proposals (Staff Paper No. 3, Social Security Administration, Oct. I969); Cohen, National Health Insurance: Problems and Prospects, 1970 Michael Davis Lecture, Center for Health Administration Studies, University of Chicago; Griffiths, Health Care for All Americans, AFL-CIO Federationist (I970). But see Falk, Beyond Medicare, 59 AM. J. Pub. Health 608 (I969). 


\section{The National Health Insurance Debate}

Interest in national health insurance has originated from a variety of sources, including the American Medical Association, the Department of Health, Education, and Welfare, the labor unions, and various economists and others working in the health field. Although all advocates implicitly accept the assumption that the present situation requires remedial action, their interest in some national health insurance plan stems from different reactions to the perceived situation. One major point of view is that a financing program without threat to vested interest groups is now politically feasible and will receive support whereas one that attempts to tamper in a major way with the conditions of professional work is doomed to defeat. Those who have come to this general position represent two very different perspectives. First there are those who fear external influences on the health care services system, and believe that changes in structure must arise from decisions made by health professionals themselves without undue government interference. Others who desire radical changes in the structure of health services, and who see no politically viable approach to obtaining such modifications at the present time, believe that the conditions for such change can develop by overloading the health services system to such a degree that a public clamor develops for a radical restructuring of the entire health field.

Since I950 the proportion of our Gross National Product devoted to health services has increased from approximately 4.6 per cent to 6.7 per cent, in substantial part as a consequence of a rapidly increasing contribution by the federal government. Any new system of national health insurance with extended coverage would add several billion dollars to present investments. Given the proportion of government payment of the total medical care bill-approaching two-fifths of the medical care dollar-it is unrealistic to believe that government will not play a larger role in the future in helping to determine how medical care will be restructured. ${ }^{3}$ The conservative forces are probably correct in their assumption that the power of government is maximal at the time of infusion of new funds, and, therefore, to have a large investment made without serious tampering with the system would leave present providers with their strength intact. The appeal of national health insurance to such organizations as the American Medical Association is probably based in part on such an assessment, since they probably anticipate that at some later point such a program might involve more vigorous interference with the practice of medicine.

As for those who aspire toward precipitating a more profound crisis-seemingly providing an opportunity for a radical restructuring of health services-it appears that their hopes may be based on rather fragile and wishful thinking. In recent years many billions of dollars were rapidly brought into the health sector, inflating the

\footnotetext{
${ }^{3}$ See generally Kissick, Health-Policy Directions for the 1970's, 282 N. ENG. J. MED. I343 (1970).
} 
medical care dollar and straining medical care resources, yet significant challenges to professional autonomy and behavior have not occurred. On what basis, then, do these proponents predict collapse? It is by no means certain that five, ten, or fifteen billion dollars more will necessarily lead to conditions provoking the anticipated political tide. Indeed, such expenditures without carefully worked out incentives may bring few improved services for medically disenfranchised groups at great cost, more over-all inflation in the medical care field, and reduction of possibilities for accomplishing significant change through stimulation of alternative forms of organization for delivery of medical services and alternative professional behavior.

In this paper I shall not assume the development of conditions for a radical restructuring of health services. I will proceed, however, on the assumption that the present crisis offers an excellent opportunity for the development of new incentives for improvement in the delivery of health services. I begin by describing some of the major difficulties presently existing in the health care system and the problems that proposals for national health insurance must realistically confront. The failures of the Medicare and Medicaid programs are attributable to the fact that they have persistently side-stepped these issues on the assumption that the provision of money alone could overcome significant failures in the organization of health care. These programs, thus, have duplicated and exacerbated the persistent deficiencies, inefficiences, and absurdities of the current organization of medical care in America. The problems are complex and particularly difficult from a political standpoint. As painful as these problems may be, the presently deteriorating situation offers little alternative but to pursue constructive change or to court disaster. The wide appreciation of this fact in government, among various third parties, and even within the health professions themselves offers some hope that constructive change is indeed possible.

\section{II}

\section{Some Notes on the Present State of Affairs}

The delivery of health care at the present time is plagued by failures in organization, lack of planning, and poor coordination among the components of care. The substantial demand for medical services characteristic of an affluent population offers physicians abundant opportunities for selling their services, however organized; and under these conditions it is not surprising that many doctors seek practice circumstances that maximize their autonomy and professional discretion and fulfill their conditions for personally satisfying work. This is a ubiquitous human tendency, and doctors cannot be faulted any more than others in our society for making the choices that are most congruent with their personal aspirations.

Hospitals, the major workplace of doctors, have undergone tremendous expansion

\footnotetext{
-For descriptions of such inefficiencies, see E. GinzBerg \& M. Ostow, Men, Money, aNd Medicine (1969); Senate Staff Report, supra note T.
} 
of their facilities and technologies and have experienced growth in both the size and complexity of their manpower pool..$^{5}$ Still dependent on doctors for patients to occupy their beds, however, hospitals have been cautious and reluctant to make new demands on physicians despite enormous difficulties in efficient operation and associated financial problems. Indeed, hospitals often have been influenced substantially in their decision making by the need to provide facilities and organizational forms attractive to their medical staff so as to retain them. In short, the operation of hospitals and medical care in general is influenced largely by the physician's definition of his needs, his professional responsibility, his concepts of autonomy, and his life style. Any serious attempt to understand the organization of medical care requires detailed attention to the doctor's perspective.

\section{A. The Physician's Perspective}

Although the health industry encompasses more than three million workers, the 300,000 doctors define and control the basic pattern of organization of health services. This hegemony stems from a variety of factors: their specialized training and prestige, their central role in health care, the tremendous demand for their services, and their resulting independence. As Freidson has noted, the key to medical authority is that the doctor not only controls his own work but has the ability and centrality to control the work of other occupations as well. ${ }^{\circ}$

The physician's perspective is one that defines medical work in terms of responsibility to individual patients, ${ }^{7}$ and the typical doctor wishes to provide optimal care without suffering infringements on his personal autonomy. In this sense doctors, like other professionals, strive to retain control over their work and the choice of the location, scope, and pace of their activities. For the most part, doctors do not regard it as their personal responsibility to see that medical care is available to all in need although many doctors would agree with such aspirations. The doctor sees his responsibilities fulfilled if he provides conscientious care to his patients, and he seeks to do so under conditions that fulfill his personal needs as well. Thus, unlike the student of medical care, he is not likely to review his effectiveness or contribution in terms of the greatest good for the greatest number. The consequences of this type of selectivity are an uneven distribution of doctors, an unbalanced division of medical functions, and a variety of inequalities in the delivery of medical care services to the population.

Government programs in health care have rarely demanded that doctors demonstrate responsibility in the charges for their services or in the manner in which they use hospitals, nor have hospital administrators been sufficiently secure in their own

\footnotetext{
${ }^{5}$ On manpower developments, see H. Greenfiedd, Allied Health Manpower: Trends and Prospects (I969).

${ }^{6}$ E. Freidson, Profession of Miedicine 47-70 (I970).

7 See, e.g., H. Becker et al., Boys in White: Student Culture in a Medical School (196r); S. Miller, Prescription for Leadership: Training for the Medical Elite (i970).
} 
power to attempt to institute rigorous controls. In the typical private fee-for-service context, doctors can sell their services as long as there is sufficient demand and the patient is willing to pay, but patients' concerns about costs and their varying ability to pay impose a degree of control. As an increasing part of the medical care bill has been paid by intermediaries rather than the patients themselves, neither doctor nor patient has been pressed or inclined to resist rising costs. ${ }^{8}$ Costs have thus mounted on every front, technology has expanded in an inefficient and unbalanced fashion, and relatively small inroads have been made in equalizing accessibility to good medical care.

It is worth noting that fiscal responsibility will require controls over the way doctors work, and insurance mechanisms by themselves are unlikely to have major impact. There are several studies that suggest that extended coverage of medical care outside the hospital by itself is unlikely to significantly affect rates of hospitalization or the use of particular medical procedures. ${ }^{9}$ However, experience in prepaid group practices suggests that when prepaid mechanisms are linked with various incentives for the physician to limit utilization, rates of hospital utilization can be significantly reduced. ${ }^{10}$ The difficult issues to decide are what rate of utilization is really appropriate for various populations, and what are the boundaries of under- and over-utilization. ${ }^{11}$ Although it is important that unnecessary utilization and medical work be curtailed, it is equally urgent to insure that those who need particular forms of care receive it.

Another element of the physician's perspective is his growing concern with technology and scientific practice. In recent years there has been a phenomenal expansion of personnel and facilities to support the growth of medicine as a scientific enterprise, and no responsible person would debate the many advantages that have accompanied this growth. But the technical growth of medicine has not been fully balanced, and too many doctors have substituted excessive technical pursuits for understanding and communicating with their patients. Just as one can fail to use appropriate laboratory tests or other diagnostic procedures, so too can one overuse or misuse them. Accompanying the growth of technology has been an uncritical acceptance that has led to the tendency toward confusing the technical means of medicine with its practice, which has many humanistic concerns. ${ }^{12}$ This emphasis on technology has also encouraged proliferation and duplication of complex technical arrangements to deal with particular disease conditions. Overinvestment in

\footnotetext{
${ }^{8}$ See McNerney, Why Does Medical Care Cost So Much?, 282 N. ENG. J. Med. 1458 (1970).

'See, e.g., Lewis \& Keairnes, Controlling Costs of Medical Care By Expanding Insurance Coverage, 282 N. ENG. J. MED. I405 (I970).

${ }^{10}$ See Densen et al., Prepaid Medical Care and Hospital Utilization in a Dual Choice Situation, 50 AM. J. Pub. Health ryro (I960); Perrott, Federal Employees Health Benefits Program (pt. 3): Utilization of Hospital Services, 56 Am. J. Pü. Health 57 ( 1966 ).

${ }^{11}$ See Health Information Foundation, Hospital Use by Diagnosis: $A$ Study in Contrasts, ro Progress in Health Services r (ig6r).

${ }^{12}$ See generally Mechanic, Changing Structure of Medical Practice, 32 Law \& Contemp. ProB. 7II (I967).
} 
such technologies is not only costly and inefficient but also results in less effective care than would be given if investment were concentrated in fewer specialized facilities operated by adequate numbers of highly specialized personnel who would have a sufficient work load to maintain and develop their special skills. ${ }^{13}$

The physician's perspective has been encouraged in large part by developments in medical schools in recent decades. With the establishment and expansion of the National Institutes of Health, vast funds for research became available to medical schools, making possible rapid expansion of their facilities and research faculty. As a consequence, a strong technological and research emphasis was encouraged, influencing the character of medical education itself. Many new medical faculty were largely researchers working in highly specialized areas and conscious of new technological developments, and frequently they were not concerned with the more wholistic problems of medical care. ${ }^{14}$ The models such faculty presented for students were ones encouraging emulation of the research orientation, and, since these were often the men to whom the largest rewards flowed, it is not surprising that they have had a profound influence on the image and orientation of medical students.

This is not to say that much of value did not flow from these developments, and there is no question but that specialization and technical development are prerequisites for the effective development of medical care. But the way in which these developments occurred created major imbalances in the medical school, and much of the early emphasis on the cultivation of the arts of patient care gave way to an excessive reliance on the laboratory and the technics of medicine. The fact that medical care is a set of attitudes and approaches as well as a set of technical procedures was frequently lost in this enthusiasm for expanding scientific developments.

One of the ironies of these developments was the fact that the community practice of medical care changed very little. Graduates of medical schools found it more difficult than ever before to translate what they had learned in the teaching hospital to the practice of medicine as it existed in the community, and one mode in which they adapted-with the encouragement of their medical professors-was to specialize in some segment of medical work..$^{15}$ Through specialization it became possible to practice in accordance with modern standards and to keep up with rapidly changing knowledge in one's own field. These trends have established the conditions for the current difficulties in providing primary medical care.

The failure of the community organization of medicine to adapt in the face of changing technology can be attributed to a variety of factors. Perhaps most important was the comfort that older doctors felt with existing arrangements and their fear

\footnotetext{
${ }^{13}$ See, e.g., H. RATNer, MEdicine 20 (Center for the Study of Democratic Institutions, 1962).

${ }^{14}$ For interesting portrayals of this phenomenon in teaching hospitals, see E. MUMFord, INTERNs: From Students to Physicians (1970) and Mirler, stipra note 7; for a more general discussion of medical education along these lines see J. Richmond, CurRents in AMERICAN MEDicine (I969).

${ }_{16}$ The family physician potential relative to the population declined from 94 to 50 per 100,000 population between I93I and 1965. See generally R. Fein, The Doctor Shortage: AN Economic Diagnosis (I967).
} 
of organized practice as an intrusion on their professional life style. The status quo was vigorously supported by organized medicine and the doctors it represented, and there were few forces in the medical profession who were inclined to challenge this powerful group. Small but important adaptations took place, as reflected in the growth of group practice, the pooling of resources among doctors for managerial purposes, and the further development of experiments with prepaid group practice. But the main current of medicine was in large part unaffected. Much of the growing public concern with the state of affairs was mitigated by the growth of voluntary health insurance, which was able satisfactorily to absorb the more educated and affluent segments of the population whose dissatisfaction could have posed the greatest threat to the status quo. Groups not covered by such insurance were insufficiently organized or vocal to pose a serious threat to prevailing patterns. Still, despite this ability of organized medicine to deal with any political threat, the dominant solo practice orientation of medical practice was strained and began to weaken. This weakening process can be expected to continue as the major foundations of solo practice are further undermined by technical developments and the growing complexity of treatment and rehabilitation.

\section{B. The Present Crisis in the Geographic Distribution of Medical Care}

A crisis constitutes a situation of challenge, the response to which determines the future fate of the system. ${ }^{16}$ The crisis in medicine may be described as one where certain expectations have developed, and the issue remains as to whether the existing system can respond in an adequate way to the demands it encounters. Standards for a viable system of medical care in our emerging society probably include (I) the availability of basic medical services to those in need regardless of social position; (2) coordination and integration of the elements of health services, including primary outpatient care, hospital care, and rehabilitation services; (3) attention not only to diagnosis and treatment of disease but also responsiveness to the personal and social circumstances affecting the patient; and (4) a commitment to the concept not only that medical care should be delivered in relation to need but that preference should be given to those modes of medical activity having the greatest impact on the health of the population. It should be evident that these generalizations are easily stated while their implementation may involve judgments that are enormously complex. Considerable gaps in our knowledge exist, but reasonable priorities can be established, on the basis of current understanding, that would facilitate a more rational approach to health services delivery than presently exists.

\section{Geographic Maldistribution of Physicians}

Health facilities and health manpower are distributed geographically in an uneven fashion. This maldistribution of physicians is the most significant problem because

\footnotetext{
${ }^{16}$ This point is nicely developed by Kissick, supra note 3 , in his discussion of potentialities resulting from new legislative developments.
} 
the physician constitutes the first formal link between the community and the health services system and is responsible for supervising the efforts of other health workers as well. The distribution of physicians has followed general population trends in that physicians concentrate in urban areas and have moved with the middle class from inner city to suburb. The unavailability of physicians is thus felt most acutely in rural areas and small towns, and in the inner core of cities where the most impoverished segments of the population reside.

A variety of factors accounts for the distribution of physicians. Like other professionals, doctors seek to live in areas that provide educational and cultural opportunities, and where they can earn a comfortable living within pleasant surroundings. Many doctors find it more comfortable and less trying to work with patients who share their cultural definitions and understandings. Moreover, as noted earlier, medical training in the context of the teaching hospital encourages a pattern of practice that requires the technology of a hospital and considerable colleague cooperation. The isolation of practice in underdoctored areas outside close proximity to an adequate hospital and colleagues is frustrating to the physician who feels he cannot implement the level of scientific training he received. Many rural practices would isolate him from a colleague network, more complex diagnostic and treatment aids, and the ancillary assistance available in more densely populated areas. Practice in impoverished areas also involves other frustrations, such as a high prevalence of drug addiction and alcoholism which may threaten the doctor, shortages of assisting personnel and resources, and the complexity of social and economic problems that affect the care of patients.

Other problems predominate in the effective use of ancillary health occupations. ${ }^{\mathbf{1 7}}$ These occupations are dominated by women workers, who either remain in the work force for a short time or who are irregular in their work patterns. Labor turnover in these occupations is very high, in part the product of marriage and child rearing, but also due to low wages, barriers to job mobility, and the inflexibility of health institutions in adapting to a part-time labor force.

It should be clear that any program for providing adequate medical care on a national level must be attentive to the problems of distributing manpower in relation to the prevalence of need in the population, although it is also evident that present trends push in the opposite direction. As the shortage of medical manpower worsens ${ }^{18}$ and the population's unmet demand for medical services increases,

\footnotetext{
${ }^{17}$ See GinzBerg \& Ostow, supra note 4; GreENField, supra note 5.

18 There has been a growing debate as to whether a doctor shortage exists. From a purely technical point of view, assuming rational organization and an instrumental approach to medical care, the position taken by Ginzbere \& Ostow, supra note 4, and MeNerney, supra note 8, that the shortage has been overemphasized has some merit. However, there is little evidence to support the assumption that the system can be made to operate efficiently under prevailing political conditions or can be made sufficiently responsive to consumer demand for more personalized care. See Mechanic, Book Review of Ginzierc \& OsTow, I68 Science 1563 (1970). Thus, Fein's estimates of a serious doctor shortage appear more realistic. See Fen, supra note I5.
} 
there are even fewer pressures on physicians to locate their practices in areas where their services are most needed, since they can sustain themselves without difficulty in most areas and can choose locations that offer optimal satisfactions. Thus, as more government funds flow into medical care services, present trends will be exacerbated rather than relieved. Any significant relocation or redistribution of medical manpower and resources will have to result from pressures brought about by explicit new public policies.

If one works on the assumption that our society is unprepared to seek redistribution of physicians through coercive mechanisms-and this is obviously the case-then it is most fruitful to consider intermediate solutions involving new incentives for redistribution. But by their very nature, noncoercive incentives are likely to have relatively little force. If such incentives are to have influence, they must be implemented in some coordinated way so that they buttress one another and so that their total impact constitutes a real basis for change. A program for a national redistribution of physicians must include attention to such matters as the recruitment of medical students, the content of medical education, the conditions for an adequate level of practice in underdoctored areas, and economic incentives for change. Each of these will be considered below in some detail after some initial considerations.

One idea increasingly advocated is the development of a National Doctors Corps. It has been suggested that doctors be given an opportunity to volunteer their service to the national health as an alternative to service in the Armed Forces. No doubt this would be an attractive choice to many young doctors, but the idea itself poses difficulties. Although doctors have always resisted coercive service, they accept the draft on the same basis as others: however unattractive such service may be, it is difficult to sustain resistance given the nature of the sanctions involved. The demand for doctors by the Armed Services is unlikely to decrease substantially, and the choice by young doctors of an alternative would probably have the effect of expanding the doctor draft which doctors would be unlikely to support. The idea of an alternative to the draft cannot be implemented on a sufficiently large scale to have an important impact on medical care. Thus we must turn to other alternatives.

\section{Recruitment of Medical Students and Medical Education}

Medical schools now find themselves in a significant financial crisis because of growing inflation and the cutbacks in federal grant funds. Most medical schools have expanded their research efforts substantially in recent decades without concomitant increases in their enrollment. With the contraction of federal funds, medical schools are finding it difficult to support their current efforts, and are reluctant to make major commitments under prevailing conditions to further respond to the nation's need for physicians. They look to the federal government for relief from their difficulties.

Inevitably the federal government will have to develop more effective mechanisms 
for sustaining the operation of medical schools, which constitute an essential national resource. It would be wise, however, to use the incentives that financing carries to insure the graduation of more doctors. For example, a condition for substantial federal funds can be expansion of medical class size; or the formula by which medical schools receive support can be geared to an evaluation of the extent to which individual medical schools are contributing their share of graduates to the total pool of physicians. Such incentives must not be crudely applied, and must take into account the distinctive qualities of particular medical schools that have achieved excellence in other areas; but, over-all, some application of the principle of "the carrot that has become a stick" seems a reasonable means of inducing action directed toward meeting public needs.

Associated with this, it would be useful to establish a National Fellowship Program for Medical Students which provides full costs and a living stipend. Such fellowships could be tied to an agreeement on the part of the recipient to practice in federally designated underdoctored areas for stated periods of time. The determination of underdoctored areas can be made by committees including representatives of the medical profession, government officials, and others. The costs of medical education are sufficiently large so that medical students are disproportionately recruited from a small segment of the population. A national fellowship program is likely to bring about a wider recruitment of students from varying socioeconomic levels and ethnic groups, and such students may have different values and orientations from those now recruited.

To insure that competent students in such a national fellowship program receive medical school places, the formula for financing medical schools should be tied to the willingness of medical schools to reserve a certain proportion of medical school places for national fellows. Recipients should meet standards sufficiently high to anticipate success in medical school, but they need not be the highest ranking students in competitive terms. Since this recommendation violates a strongly held value in universities--that admission should be geared solely to the academic qualifications of the candidate-some elaboration is required. Medicine is an applied profession, and its work must be evaluated in terms of its direct service to the public. Although the highest academic standard may be required for medical research and medical school teaching, the work of a good doctor involves many qualities other than academic ones. The willingness of the physician to serve those in need or the kinds of attitudes he assumes toward patients may be more important than small differentials in grades or performance on the Medical College Admissions Test. It is reasonable to select medical students from a pool of eligibles established on the basis of aptitude for medical studies. Choice within the pool, however, would depend on criteria other than modest differences in past academic performance. Indeed, studies of the physician's performance show little relationship between scholastic performanceonce the basic minimum level had been reached-and the effectiveness of the doctor 
in performing his functions. ${ }^{19}$ I should add that there is a long history of universities' and medical schools' taking other criteria into account-as in the preference given to children of doctors or children of alumni-and all that is really advocated here is that such preferential treatment reflect public needs and public goals in contrast to private ones.

Also, much greater balance is necessary in medical education between developing technical proficiency on the part of students and teaching how these skills can be translated into effective medical care in the community. The realities of community practice vary from those of the teaching hospital, and doctors must learn how to provide effective medical care within the real constraints they are likely to encounter in community contexts. The growing tendency of medical schools to assume greater primary care responsibilities provides the opportunity to develop practice laboratories in which young doctors may learn to practice a high level of technical medicine in a fashion responsive to the needs of patients and the community. The medical student should become acquainted with the potentialities and difficulties of practice under varying organizational arrangements; and if medical schools can provide viable models for general community care, doctors may be more inclined to take on these types of practice following their training.

\section{Medical Organization in Underdoctored Areas}

Just as it is necessary for medical schools to develop varying models of practice for educational purposes, so it is also necessary that underdoctored areas develop the resources and other conditions conducive to a good and satisfying medical practice. Many of the remaining doctors in rural areas and in the inner city are disproportionately old, and they are not being replaced by younger doctors, ${ }^{20}$ who aspire to practice a higher level of medicine than is often possible in many such areas. What is often lacking is a medical structure and supporting services that facilitate the doctor's efforts and that allow him to use effectively the skills he has learned. Government subsidy for the development of such supporting facilities could be extremely important in attracting doctors to such practice.

It is possible to develop exciting and effective opportunities for practicing a high level of medical care with room for considerable experimentation and innovation. The necessary organizational development would include the concentration of physicians, nurses, and other health workers in facilities providing good preventive, diagnostic, and treatment services. A variety of models already exists for developing regional health facilities, community health centers, mobile teams associated with regional complexes, and the like, and there is no dearth of experience around the world that provides perspectives on both the potentialities and the difficulties of vary-

\footnotetext{
${ }^{10}$ Peterson et al., Analytic Study of North Carolina General Practice (pt. 2), 3 I J. Mad. Educ. I (1956).

${ }^{20}$ See generally Sidel, Can More Physicians Be Attracted to Ghetto Practice?, in Medicine in THE GHETTO I7I (J. Norman ed. 1969).
} 
ing approaches. ${ }^{21}$ There are many different approaches that can be taken, and probably in each case the strategies should be geared to the special problems of the area and to the facilities already available. Given the tremendous difficulties in providing medical services to underdoctored areas, it is reasonable for government to give high priority to the development of a viable health structure that would be attractive to medical manpower and that would make optimal use of paraprofessional workers. Government must, however, be attentive to the dangers of having such structures defined as providing a lesser level of medicine than is available to other population groups.

\section{Development of Economic Incentives}

The use of economic incentives for achieving redistribution of physicians has been used formally in some countries and informally in our own. In Britain, ${ }^{22}$ for example, general practitioners establishing practices in underdoctored areas receive additional income above their usual remuneration, and under some circumstances they are assured a particular income level. Various communities in the United States have offered physicians free practice facilities, guaranteed incomes, and a variety of other attractive incentives. For the most part, such incentives are not particularly effective without other changes in the conditions of practice. In England, economic incentives are buttressed by closing certain overdoctored areas from new practices, which at least serves to insure some minimal redistribution. However, these restrictions involved areas encompassing only seven per cent of the total population in I 968,23 and in large part doctors are free to practice where they choose.

Although it is unlikely that the United States would restrict doctors from practicing in areas of their choice, as a matter of public policy it would not be difficult to develop a tax policy that gives tax advantage to those who choose to practice where they are most needed. Such incentives by themselves-unless extremely large-would probably make no substantial difference but when linked with other reforms might constitute significant elements of an over-all plan.

There are, of course, other mechanisms available to restrict practice choice. Various states could control the establishment of new practices through their licensing function, although this would entail a perhaps undesirable change of the licensure program from one of competence certification to a kind of public utility regulation. Similarly, it is conceivable that the control over the granting of hospital privileges could serve as a mechanism that discourages doctors from practicing in relatively

\footnotetext{
${ }^{21}$ For interesting contrasts of some varying approaches, see J. FRY, MEDICINE IN THREE Societizs: A Comparison of Medical Care in the USSR, USA, aNd UK (ig69); M. Roemer, The Organization on Medical Care Under Soctal Securtty (I969); and E. Weinerman, Social Mapicine in Eastern EUROPE ( 1969$)$.

${ }_{22}^{2}$ R. Stevens, Medical Practice in Modern England 223 (1966).

${ }^{28}$ See Departasent of Health and Soctai Security, Annual Report for the Year 1968, Casnd. No. 4 roo, at 90 (1969).
} 
overdoctored areas. Given the general scarcity of doctors, however, it is difficult to see what political forces could bring about such use of the hospitals' powers.

\section{III}

\section{Developing a Mechanism for Implementing Priorities in Medical Care Delivery}

Medical care is diffuse by its very nature, combining technical operations with a variety of human concerns. The total package is difficult to define, and it is even more difficult to determine whether some part of it is worth paying for in an amount sufficient to cover its cost. Yet we know that the typical practice of medicine includes considerable use of medical and technical procedures that are dangerous and costly beyond any conceivable value to the patient. Since it is not difficult to find conflicting opinions concerning the management of almost any disease, ${ }^{24}$ the field of the doctor's work is characterized by considerable murkiness which interferes with the establishment of priorities. Yet it seems perfectly reasonable that those who pay the bill ought to have some basis for determining what is worthy of payment, and that procedures not worth their cost, either in general or in particular circumstances, ought to be discouraged in a time of general scarcity of medical resources. A precedent for professional evaluation of effectiveness exists in the evaluations made by scientific committees of the National Academy of Science-National Research Council of the efficacy and safety of various therapeutic agents.

How, for example, does one justify a rate of more than 600 tonsillectomies per I00,000 population performed in the United States in $1965,{ }^{25}$ when the medical literature contains carefully controlled studies demonstrating the procedure to be both potentially dangerous to the patient and medically worthless except in very limited situations? Further, ${ }^{26}$ how does one justify a program of medical care insurance or financing that pays for such procedures and that may have the effect of increasing their prevalence? ${ }^{27}$ Since we know that particular dubious procedures are performed with great frequency, would it not be reasonable to require some demonstration of the need for such procedures before public funds are expended? Of course, in endeavors where clinical judgment of particular circumstances is important, it may be prudent to adopt a liberal definition of effectiveness and worth, but review of procedures frequently misused is likely to conserve funds and improve the over-all quality of medical activity. The fact of review itself is likely to make doctors more conscious

\footnotetext{
${ }^{26}$ For a fascinating discussion among sophisticated experts concerning opposing approaches to the treatment of such common conditions as hypertension, ulcers, emphysema, rheumatoid arthritis, and other diseases, see Controversy in INTERNAL Medicine (F. Ingelfinger et al. eds. Ig66).

${ }^{25}$ Bunker, Surgical Manpower: A Comparison of Operations and Surgeons in the United States and in England and Wales, 282 N. ENG. J. MED. I37 (1970).

${ }^{20}$ See Bolande, Ritualistic Surgery-Circumcision and Tonsillectomy, 280 N. ENG. J. Med. 593 (1969).

${ }^{37}$ As Bunker, supra note 25 , shows, the rate of such procedures in the United States is double the rate in England and Wales.
} 
of the implications of their decisions and more cautious in the use of unnecessary procedures that involve risks of harm.

The idea of review is one that professionals find unattractive, and I have no doubt that my remarks on the topic will be upsetting to many physicians. It will be argued that such review is cumbersome, time-consuming, and inefficient, and a disincentive to necessary work and innovation in treatment. I should note that prereview exists within various social security systems in the world, and has been used effectively to control unnecessary work by physicians and dentists within these systems. ${ }^{28}$ I believe that these mechanisms deserve careful attention and research, and that some modification of them might have something to contribute within the context of our existing system of medical care. I might add that review of certain procedures has been quite common in the United States, most notably in the case of abortions before the current climate of change set in. ${ }^{29}$

In considering the definition of appropriate and inappropriate procedures and those worthy of public support, several distinctions must be kept in mind. Many medical activities are ameliorative and supportive, and the extent to which such services are sought and used is heavily dependent on consumer decisions. Other procedures and activities depend largely on the doctor's judgment. Still others occupy a hazy middle ground involving negotiations between patient and physician, and considerable client control may be evident in pushing the physician toward a particular course of treatment. ${ }^{30}$ There are a variety of options available in developing mechanisms for reviewing or sharing the cost of services whose utilization is effectively determined by the consumer. Experience in other countries suggests that the viability of any particular mechanism of control of such costs depends on the habits and attitudes of the population involved and that it is difficult to generalize about such experience from one country to another. ${ }^{31}$

Financial barriers to medical care affect rates of utilization. Many doctors feel that the total elimination of cost to the patient stimulates trivial and inappropriate consultations, although the evidence in the British case does not disclose an excessive rate of utilization when such barriers are removed. ${ }^{32}$ The intermediate solution adopted in Sweden requires a small percentage of the fee to be paid by the consumer, and this may cut down frivolous consultations without creating significant cost barriers to needed medical care, since full benefits are available for those who cannot afford to pay. The Swedish case is difficult to evaluate since there is a considerable shortage of general physicians; and the difficulty of obtaining an appointment with a doctor and long waiting periods in seeing him probably pose a much more sig-

\footnotetext{
${ }^{28}$ See, e.g., W. Glaser, Paying the Doctor: Systems of Remuneration and Their Effects (I970).

${ }^{29} \mathrm{See}$ L. LAdER, Abortion 27 (I966).

${ }^{80}$ See genetally E. Freidson, Patients' Views of Medicat Practice (ig6i).

'see Glaser, supra note 28.

${ }^{22}$ A. Cartwright, Patients and Their Doctors: A Study of General Practice 33-35 (1967).
} 
nificant barrier to utilization. ${ }^{33}$ Outpatient care constitutes the least expensive type of medical service, and a case can be made that patients ought to be encouraged to seek medical assistance whenever they feel the need, and that the doctor and other health workers ought to use such occasions, when the problem is not serious, for establishing an educational and preventive care relationship.

The most costly element of medical care is hospital care, and admission is fully dependent on the consent of the physician. Prepaid care may be organized in such a way that primary services are readily available, but there is relatively little incentive for the doctor to hospitalize the patient or to perform unnecessary medical and surgical procedures. $^{34}$ In contrast, many of the payment schemes, including Medicare and Medicaid, provide strong incentives for unnecessary hospital care, and abuse is particularly likely when medical services are operating at less than full capacity. ${ }^{35}$ In weighing relative costs it appears clear that excessive utilization, if it is to occur, 1s most appropriate and least harmful at the primary care level and most expensive and risky at the hospital level. Moreover, since a medical decision is a prerequisite for hospital care, it is primarily in this area that effective controls can be realistically implemented.

Government programs ought not to pay for procedures that informed medical opinion defines as worthless. In the past physicians have opposed the extension of benefits to chiropractic services, but perhaps some medical procedures ought also to be looked at in the same light. Some procedures that have value in some circumstances but involve large costs and large potential risks to patients and are known to have a high prevalence of misuse might benefit from prereview by an appropriate medical committee before the work is undertaken and payment authorized. Still other procedures involving less danger and cost but considerable abuse might be controlled through periodic informational audits. It is not my purpose to suggest how such mechanisms should operate, but it seems reasonable to anticipate that satisfactory procedures can be developed that would protect the patient and the public purse more appropriately. Whatever these mechanisms are, they should be developed and administered largely by physicians, and should reflect informed professional opinion. There are problems in specifying what is and is not necessary, and such decisions will often depend on the facts of the individual case. However, abusive practices are not too difficult to locate, and the need for added controls is indicated by the growing evidence that a small proportion of doctors can seriously threaten the viability of a major program. ${ }^{36}$

\footnotetext{
${ }^{33}$ See R. Andersen et al., Medical Care USE in Sweden and the United States: A Comparative ANALYSIS OF SYSTEMS AND BEHAVIOR (r970).

8' Saward, "The Relevance of Prepaid Group Practice to the Effective Delivery of Health Services," paper presented at the I8th Annual Group Health Institute, Ontario, Canada, I969.

${ }^{35}$ See generally SENATE StAFF REPORT, supra note I.

${ }^{80}$ See Lewis \& Keairnes, supra note 9. They note that "Two to 3 per cent of the physician population can create a 'leak' in the system through which an inordinate amount of dollars can pour without any improvement in the overall quality and quantity of health care rendered to society." Id. at I4I2. This is
} 


\section{IV}

\section{Developing Criterua for Evaluating the Effectiveness of Healte Care Programs}

How we know a good medical product when we see one and how we identify alternatives worthy of development are larger problems than they may appear. Relatively little effort has been devoted to identifying and refining criteria by which to evaluate competing programs of medical care, and few rigorous measures exist. In this final part of the discussion I shall briefly suggest some major dimensions in comparing alternative forms of delivering medical care. Among the criteria used from one discussion to another are the following: relative mortality and morbidity; patient satisfaction; professional satisfaction; cost; stimulation of new investments; coordination and integration of elements of care; recruitment and retention of personnel; quality of special services (such as mental health services); capacity for innovation and adaptation; accessibility of services; effectiveness of manpower distribution; quality of controls over professional work; incentives for abuse of services; and continuity of care. Many of these criteria are misunderstood and applied carelessly, and a brief discussion of some of these criteria is in order.

One of the ways in which comparisons are most frequently attempted between different programs is to compare relative mortality and morbidity rates. ${ }^{37}$ Although the quality of medical care has some relationship to infant and adult mortality, for the most part differences in rates reflect variations in the quality of life and the environment and cannot be traced directly to the provision of medical services. ${ }^{38}$ Any comparison on mortality must be sensitive to the characteristics of the populations served, and must take account of variations in other factors conducive to illness and death among the populations being compared. Sensitive use of mortality data can be valuable. For example, if it can be demonstrated that a particular system of medical services working with a population of measurably greater difficulty achieves rates that are superior to those achieved with more privileged populations, such information is particularly suggestive. But rates even specific to particular procedures must be inspected carefully since favorable rates may reflect the unwillingness of a medical service to take difficult problems where risks of mortality or chronicity are very high. Superficial examination will show, for example, that midwives and home delivery arrangements yield lower infant deaths than special obstetrical units in hospitals. It is clear, however, that these services work with different types of risks, and interpreting the outcome without attention to the inputs contributes little to our understanding.

\footnotetext{
based on their own study where they found that $8.7 \%$ of the physicians received $44 \%$ of all specialbenefit dollars.

${ }^{87}$ See generally D. Rutstein, The Coning Revolution in Medicine r5-28 (1967).

${ }^{88}$ For a review of factors affecting infant mortality, see D. Mechanic, Medical Socrology: A Selective View 237-57 (ig68). See also S. Shapiro et al., Infant, Perinatal, Maternal, and Childhood Mortality IN the UNTted States (Ig68).
} 
Morbidity is more difficult to measure, and relative rates of morbidity may reflect the availability of medical services for identification and diagnosis of disease. Specific morbidity evaluations may be useful, as in comparisons between iatrogenic reactions, the rate of occurrence of preventable conditions among persons under care, and the like. But even these rates tend to be tricky in that evidence of success and failure depends to some extent on the ambitiousness of the cases which doctors are willing to tackle. Careful comparative work is possible and extremely useful, but it is not easily done.

A common criterion by which the success of health service systems is evaluated is the degree to which the consumer feels his needs are successfully met and is satisfied with the care he receives. Various studies show that consumers place high value on the skill of their physician and his interest in them. It is primarily the latter which can be evaluated by the consumer, and judgments of the quality of care by consumers often reflect the doctor's personality, his accessibility, and his attention to the patient's wishes. Patients are frequently not in a position to understand the quality of care potentially available to them, and often form their judgments on the basis of past experience with physicians. In general, patients report considerable satisfaction with their personal medical care, although they are much readier to criticize the system of care in general. Some dissatisfaction arises among consumers when doctors are less amenable to client control, as in prepaid group practice, but the doctor's orientation to his colleagues' standards under such circumstances may be conducive to higher quality medical care. ${ }^{39}$

Since patients are reluctant to report dissatisfaction with their own physicians, one can benefit by measuring dissatisfaction of consumers indirectly. The rising rate of malpractice suits in American medicine probably reflects in part the growing impersonality of the relationships between doctors and their clients. ${ }^{40}$ When close personal relationships exist, persons are loath to bring suit even when the doctor has made significant errors; when the relationship is weak, frustration may readily lead to legal action. Other possible criteria of dissatisfaction include the rate of use of facilities outside the patient's medical care system, as occurs when patients in prepaid plans seek additional private care $\mathrm{e}^{41}$ and when consumers in the National Health Service, for example, seek private care. ${ }^{42}$ All such rates are influenced as well by factors other than satisfaction and must be used sensitively and cautiously, but they can alert us to the aspects of organization that arouse consumer dissatisfaction and breakdowns in medical service. Although consumer satisfaction is not the central

\footnotetext{
${ }^{80}$ See Freidson, Medical Care and the Public: Case Study of a Medical Group, 346 Annars 57 (1963).

${ }^{\circ}$ See genterally Staff or Subcoman. on Executive Reorganization of the Senate Comm. on Government Operations, goth Cong., ist Sess., Meoical Malpractice: The Patient vs. the Physician passim (Comm. Print 1969); R. Blum, The Management of the Doctor-Patient Relationship (ig6o).

${ }^{4}$ See G. Stluer, Fammi Medical Practice 233 (Ig63). See generally Freidson, supra note 30.

12 See generally S. Mencher, Private Practice in Britain: The Relationship of Private Medicat Care to time National Heazth Service (Ig67).
} 
goal of medical care, the development of significant dissatisfaction is a serious threat to the continuity of medical care and its over-all effectiveness.

A particular pattern of medical care can also be frustrating and dissatisfying to the doctor and other professionals, but frequently doctor and patient satisfactions are not related to the same factors. Ideally, the patient would like his personal doctor available to him at any time in need, willing to visit his home, and responsive to his wishes; but many doctors prefer relief from total responsibility, are reluctant to make house calls, and feel their decisions should reflect their professional judgment and not patient pressures. Many factors influence professional satisfaction, including the doctor's remuneration, the conditions of work, his status in the community, and his autonomy. ${ }^{43}$ Doctors have considerable political power which they use to protect the conditions they value, and any viable system of organization must insure to some extent the conditions doctors prefer. Alienation of the physician is disruptive to the smooth functioning of a medical care program and, under conditions of manpower shortage, may lead to work mobility. Doctors around the world are becoming more militant in expressing their interests, and the threat of doctor strikes is increasing. Moreover, there is tremendous elasticity in the amount and the quality of the work a physician can do, and it is important that incentives for effort and excellence be maintained. ${ }^{44}$

The competition for medical manpower is sufficiently fierce among varying programs within the United States and among nations that the imposition of controls and changes in the organization of practice must take into account the recruitment and retention of personnel. Organizational change must be based to some extent on the conditions that are likely to attract and retain professional resources, and this is particularly true when programs must compete for scarce manpower with alternative programs. A dilemma may present itself in that mechanisms that may be conducive to more effective health care, such as the imposition of controls on professional work or the making of care more easily accessible (which also increases the possibilities for abuse), may be perceived as creating unattractive conditions for professional work, and programs instituting such mechanisms may have difficulties in attracting sufficient doctors.

All organizational systems, as they grow in complexity and differentiation, have problems in integration and coordination. Considerable resources must be devoted to maintaining communication, the flow of information, and a clear set of goals. Medicine is no different, and considerable attention is required for maintaining the continuity of care. The ability effectively to use special services such as physical

${ }^{4}$ See genterally Mechanic, General Medical Practice in England and Wales: Its Organization and Future, 279 N. ENG. J. MEd. 680 (1968); Mechanic, Practice Orientations Among General Medical Practitioners in England and Wales, $8 \mathrm{MED}$. CARE I5 (1970); Mechanic, Correlates of Frustration Among British General Practitioners, II J. Health \& Soc. Behav. 87 (1970).

"For an interesting argument on this point see Bailey, Philosophy, Faith, Fact and Fiction in the Production of Medical Services, 7 INQuIRY 37 (I970). 
rehabilitation, mental health, and the like as part of the total flow of services contributes in important ways to the over-all care effort.

Since there are always limited resources in the real world, and health must compete with other priorities for the resources available, the question of cost is always paramount. Different forms of organization provide varying outputs at similar costs, and we obviously must strive to get as much for our investment as we can. But there are other aspects of the issue as well. Different forms of organization may have differential capacities to attract private investment for development and innovation, and, to the extent that health is defined as a priority deserving greater attention, the ability of health care plans to grow in an effective way may be worth a certain degree of inefficiency and confusion..$^{45}$ In any case, capacity for innovation and investment potential are extremely difficult indicators to measure; as listed evaluation criteria, they at least alert us to issues that we should not ignore.

As we look toward the future of health organization in America, there is much that lacks focus. Many of the issues at stake are intricately linked, and their piecemeal discussion by its very nature is deficient. Without some clear concept of the over-all system and its priorities, it is difficult to specify the necessary manpower needs, the way in which different forms of manpower will interrelate, the kinds of physical facilities necessary, the types of new paraprofessionals that can fill gaps, and many other items of importance. If we work with the concept of a "personal doctor," then one set of priorities seems reasonable; but if we work with concepts of hospital-based primary practice, health centers, or more organized health teams, then quite another approach seems to be of greatest advantage.

In the final analysis, the development of the health services system will very largely depend on the political dialogue and on various kinds of political compromises taking into account government expenditures, political power, existing economic interests, and professional organization. Therefore, it is the height of fancy to believe that we can prescribe entirely new models of delivering health services that will replace the existing system. Even the limited proposals presented in this paper would be enormously difficult to implement, and the future pattern of health services in the United States will be largely woven out of already existing elements and traditions. Change will evolve with new events and new pressures, and we will do well if we can use such conditions to develop new competing structures for those professionals who are dissatisfied with present alternatives and for those population groups who are relatively disenfranchised under the current organization of health care.

\footnotetext{
${ }^{65}$ For an argument along these lines see Anderson, Health Services Systems in the United States and Other Coutntries-Critical Comparisons, 269 N. ENG. J. MED. 898 (rg63).
} 